\title{
Chronic Mesenteric Ischemia: Differential Vascularsurgical Therapy and Its Outcome in a Single-Center Observational Study
}

\author{
Mohamed Essa $^{\mathrm{a}}$ Frank Meyer $^{\mathrm{b}}$ Robert Damm ${ }^{\mathrm{c}}$ Zuhir Halloul ${ }^{\mathrm{a}}$ \\ aDivision of Vascular Surgery, Department of General, Abdominal, Vascular and Transplant Surgery, \\ Otto-von-Guericke University with University Hospital, Magdeburg, Germany; ${ }^{b}$ Department of General, Abdominal, \\ Vascular and Transplant Surgery, Otto-von-Guericke University with University Hospital, Magdeburg, Germany; \\ 'Department of Radiology and Nuclear Medicine, Otto-von-Guericke University with University Hospital, \\ Magdeburg, Germany
}

\section{Keywords}

Chronic mesenteric ischemia - Open reconstruction · One-/ two-vessel reconstruction · Antegrade/retrograde reconstruction

\section{Abstract}

Aim: The aim of this study was to investigate short-/longterm vascularsurgical patency and the outcome in chronic mesenteric ischemia (CMI) depending on the mesenteric revascularization technique and reflecting real-world data. Methods: This retrospective single-center observational study registered all patients who had undergone open vascularsurgical reconstruction because of CMI at a tertiary German university hospital comparing 1-versus (vs.) 2-vessel as well as antegrade versus retrograde reconstructions. Results: In total, 35 patients were enrolled (mean [ \pm SD] age, $64 \pm 13$ [range, 45-83] years; sex ratio [m:f], 16:19 [46:54]) over 12 years. Three patients with symptoms of mesenteric ischemia because of rare causes (radiation-induced and median arcuate ligament syndrome) have been excluded. While $51 \%$ of patients underwent 1-vessel reconstruction, 49\% underwent 2 -vessel reconstruction. There was a trend of (i) more perioperative complications in the 2 -vessel group ( $88.2 \%$ vs. $55.6 \%$, $p=0.06$ ) and (ii) higher morbidity at 1 year in the 2-vessel versus 1 -vessel group $(57.1 \%$ and $42.9 \%$, respectively; $p=$ $0.466)$, while the morbidity of the 2 -vessel versus 1 -vessel group at 5 years (100\% vs. $33.3 \%$ ) was significantly different $(p=0.009)$. The mortality was greater in the 2 -vessel versus 1 -vessel group as it was significantly different in the early postoperative period (31.3\% vs. $0, p=0.016)$ and at 1 year
\end{abstract}

karger@karger.com www.karger.com/vis

Karger $\%$

bOPEN ACCESS
(C) 2021 The Author(s)

Published by S. Karger AG, Basel

This article is licensed under the Creative Commons Attribution 4.0 International License (CC BY) (http://www.karger.com/Services/ OpenAccessLicense). Usage, derivative works and distribution are permitted provided that proper credit is given to the author and the original publisher.
( $50 \%$ vs. $0, p=0.005)$ and 5 years ( $100 \%$ vs. $11 \%, p=0.003$ ). Regarding overall survival, the 1 -vessel group showed a significant superiority above the 2 -vessel group $(p=0.004)$. Actually, there was no significant difference of early postoperative morbidity comparing the retrograde and antegrade group ( $p=0.285$ ) as well as at 1 year and 5 years $(p=0.715$ and $p=0.620$, respectively). In addition, there was no significantly different postoperative mortality in antegrade versus retrograde group at each time. Specific and general complication rates were $62.9 \%$ and $57.1 \%$, respectively, resulting in an overall morbidity of $77.1 \%$ (mortality, 20\%). Conclusion: The vascular surgeon should be prepared to perform various procedures of mesenteric reconstruction to tailor the operative strategy to the specific needs of the individual patient.

\footnotetext{
(c) 2021 The Author(s)

Published by S. Karger AG, Basel
}

\section{Introduction}

Mesenteric ischemia is a rare but severe disease, which is encountered during vascular surgery practice. This disorder is either acute or chronic based on the acuity and duration of symptoms. Chronic mesenteric ischemia (CMI) is a chronic and insidious process, which usually progresses over several months. Those patients usually would have undergone an extensive diagnostic workup for other suspected etiologies [1].

The first description of mesenteric vascular occlusion was attributed to the pathologist Antonio Benivieni from Florence in the later part of the fifteenth century [2]. CMI secondary to arterial insufficiency was first recognized 
Fig. 1. Contrast-enhanced multi-slice CT showing a CT-slice of a sagittal reconstruction in a patient with high-grade stenosis of the $\mathrm{CA}$ at its origin ( $>70 \%$ reduction of arterial diameter) and occlusion of the proximal SMA (left) and a 3-D reconstruction of the same patient (right) - red arrow represents the CA-stenosis, and light blue arrow represents the SMA-occlusion (from the Department of Radiology and Nuclear Medicine, University Hospital of Magdeburg [Germany]). SMA, superior mesenteric artery.
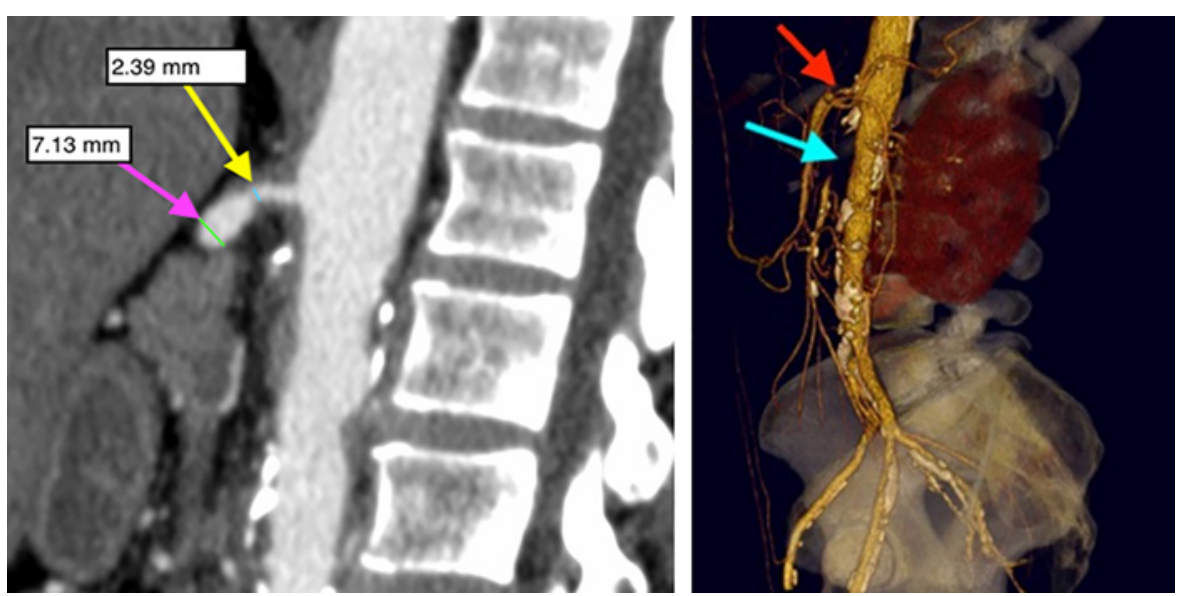

and described by Chienne [3] in 1868 followed by Councilman [4] in 1894 with the anatomical description of the celiac trunk and superior mesenteric artery (SMA) occlusions. CMI was first described as "abdominal angina" in 1918 by Goodman [5]. In 1958, the first successful open repair for CMI was performed by Shaw and Maynard [6], and they reported 2 cases successfully treated using thromboendarterectomy. Technically, more successful procedures, such as Dacron bypass grafting from the infrarenal aorta to the SMA, were described in 1962 by Morris et al. [7]. Moreover, antegrade aortovisceral bypass and transaortic visceral thromboendarterectomy were described in 1966 by Stoney et al. [8]. The French advanced a new technique to revascularize the SMA, often in association with a reconstruction of the infrarenal aorta using retrograde bypass in a left retroperitoneal $\mathrm{C}$-shaped route behind the renal pedicle to revascularize the SMA in an antegrade manner. It is often called "French bypass" [9].

According to some estimations, up to $95 \%$ of cases of CMI are due to atherosclerosis. Nonatherosclerotic causes account for $5-10 \%$ of all cases of CMI [10], such as aortic dissection, retroperitoneal fibrosis, vasculitis, and postradiation exposure [11]. The majority of patients (75\%) are smokers. About one-third of patients have hypertension and hyperlipidemia. Approximately $10 \%$ of patients are diabetic [12]. Open surgical treatment using bypass was considered the gold standard of treatment in the past. However, the endovascular treatment, consisting of percutaneous transluminal angioplasty and stenting, has emerged recently as an alternative treatment modality for CMI [13]. Several studies recommend singlevessel reconstruction using the autologous vein and a retrograde approach with bypass grafts originating from the infrarenal aorta [14]. The aim was to review more than 12-years' experience of open vascularsurgical treatment for patients with CMI from a single institution, in particular, the short- and long-term vascularsurgical outcome depending on the mesenteric revascularization

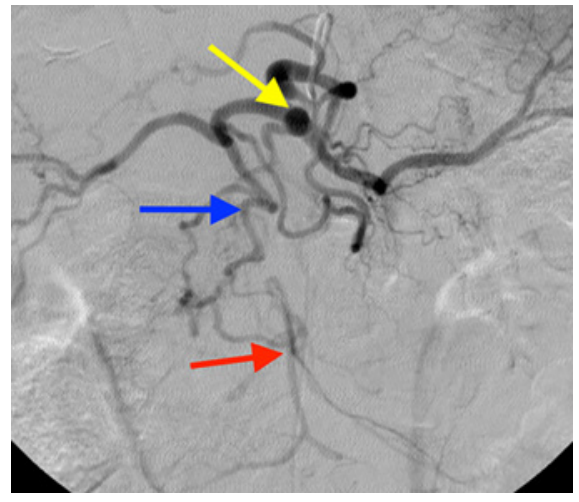

Fig. 2. Selective angiography representing a long-standing obstruction of the SMA with well-developed collaterals through the GDA (CA: yellow arrow, GDA: blue arrow, and SMA: red arrow) (from the Department of Radiology and Nuclear Medicine, University Hospital of Magdeburg [Germany]). SMA, superior mesenteric artery.

technique using 1 vessel or 2 vessels and either antegrade or retrograde flow direction of reconstruction as well as reflecting real-world data.

\section{Methods}

All consecutive patients who had undergone an elective open vascular reconstruction of CMI by the vascularsurgical team at a (tertiary) university center of (endo-)vascular surgery in Germany over a defined period of time were:

1. enrolled in this systematic retrospective uni-center observational study for quality assurance to reflect daily vascularsurgical practice as a contribution to research on clinical care (design), and

2. documented in a clinical database.

Any form of CMI was considered (inclusion criteria). Nonocclusive mesenteric ischemia, mesenteric venous occlusion, acute mesenteric ischemia, or visceral artery reconstructions for aneurysmatic disease and patients with mechanical compression of the celiac artery by the median arcuate ligament were excluded (exclusion criteria). 
Repairs utilizing bypass conduit originating from the supraceliac aortic or transaortic endarterectomy were considered antegrade. Inflow originating from the distal aorta or iliac artery was considered retrograde. The patients' group was followed up initially at 3 months and then once yearly. The presence or absence of change in clinical symptoms including postprandial abdominal pain, weight loss, and food fear was determined. Mesenteric duplex ultrasonography was the first diagnostic tool to consider if there was a clinical suspicion of recurrent symptoms. Further investigations including CTA, MRA, and DSA are considered as shown in Figures 1 and 2.

Nonpersonal-specific anonymized data had been gathered and used in the current study. The follow-up endpoint was either loss from follow-up or death. A Medline/PubMed search from early 1990 through June 2018 was conducted, depending upon search criteria of CMI, risk factors, bypass, preoperative, intraoperative, and open reconstruction. This search yielded around 80 articles meeting the authors' primary interest. Every study or article presenting any form of at least 1 risk factor correlation with the clinical outcome after open mesenteric reconstruction of CMI was included as illustrated in online supplementary Table 1; see www. karger.com/doi/10.1159/000519423 for all online supplementary materials.

The diagnosis of CMI is based primarily on clinical symptoms and supported by imaging findings, following the exclusion of other potential intestinal disorders. CT accurately demonstrates calcified and noncalcified plaque causing arterial stenosis or occlusion, typically in the proximal CA and SMA [15].

All 3 mesenteric arteries "CA, SMA, and IMA" were assessed either as obstructed or stenotic. High-grade stenosis of visceral arteries was defined as decreased vessel diameter of $>70 \%$ [16].

Several techniques were used to reconstruct the diseased visceral arteries either as 1 or 2 mesenteric artery repairs. The reconstruction was performed either in an antegrade or retrograde fashion using usually a transperitoneal and sometimes a retroperitoneal approach. Graft size was based on the diameter of the CA and SMA. If reconstruction of the CA and SMA was planned, a preformed Y-graft was used. If the entire celiac trunk was occluded or diseased, the preferred target artery was the common hepatic artery [17]. A mesenteric bypass was used using a venous graft in some cases if appropriate venous material was available either mesenteric vein or more commonly great saphenous vein, and those patients had elevated risk for wound infection. A retrograde reconstruction was considered for patients with high risk for cardiovascular events during aortic cross-clamping and for those with extensive calcification of the supraceliac aorta. The retrograde bypass originated either from the iliac artery, the infrarenal aorta, or even aortic prosthesis directly or in a C-shaped configuration. Either a polyester (Silver Graft ${ }^{\circledR}, \mathrm{B}$. Braun Deutschland GmbH \& Co. KK, Berlin, Germany), ePTFE (PROPATEN ${ }^{\circledR}$, W.L. Gore \& Associates, Newark, DE, USA), or venous graft was chosen for the bypass. Mesenteric endarterectomy was done in a few cases with closure of the arteriotomy using a xenogenic patch (XenoSure ${ }^{\circledR}$, LeMaitre Vascular, Burlington, VT, USA).

Primary patency was defined as symptom relief and was considered the sole determinant of successful therapy. Clinical patency was regarded as asymptomatic patients postoperatively, independent of graft patency, which might be proven radiologically to be occluded. Secondary patency was defined as a symptom relief after secondary intervention following the primary operative procedure in the follow-up period. The possible perioperative, in particular, postoperative complications were considered part of peri-/ postoperative morbidity, which occurred from the first postoperative period until the discharge of patients.
Table 1. Anatomical distribution for pathologies of celiac axis (celiac), SMA, and IMA

\begin{tabular}{ll}
\hline Occluded/stenotic & Patients, $n(\%)$ \\
\hline Celiac/SMA/IMA & $12(31.6)$ \\
Celiac/SMA & $17(44.7)$ \\
SMA/IMA & $6(15.8)$ \\
Celiac/IMA & $1(2.6)$ \\
SMA & 0 \\
Celiac & $2(5.3)$ \\
\hline
\end{tabular}

Celiac, celiac axis; SMA, superior mesenteric artery; IMA, inferior mesenteric artery.

\section{Statistical Methods}

The statistical evaluation was carried out using the software SPSS Statistics, version 24.0 (SPSS Inc., Chicago, IL, USA). Nonparametric tests were performed to determine whether there was a significant difference between the findings and the individual variables. Survival and patency rates were calculated using the Kaplan-Meier assessment method. Univariate statistical comparisons using contingency table analysis (Pearson's $\chi^{2}$ test) were made between each of the directionality of reconstruction (antegrade or retrograde) and the number of reconstructed arteries (either 1 or 2 arteries), regarding the development of complications postoperatively. A statistically significant difference was ascribed to a $p$ value of $<0.05$.

\section{Results}

From 2005 to 2018, 45 patients were identified who had undergone mesenteric revascularization for CMI. Eight patients who had received revascularization of acute on top of CMI and 4 patients who had undergone mesenteric reconstruction because of another cause such as combined visceral arterial aneurysms were excluded. Thus, 33 patients remained for final analysis. Two patients underwent a second mesenteric revascularization as a result of recurrent symptoms and graft failure, so there was a total procedure's number of $n=35$.

The mesenteric reconstruction was performed slightly more common in women $(n=19,54 \%)$ than men $(n=16$, $46 \%)$. The mean age of patients (mean \pm SD) was $65 \pm$ 11.87 (range, 45-83) years.

Atherosclerosis was the cause of CMI. The most frequently reported symptoms were postprandial abdominal pain in all patients and $>10 \%$ with body weight loss during the last 6 months ( $n=30$ patients, $86 \%)$, with a mean \pm SD of BMI as $20.97 \pm 4.28 \mathrm{~kg} / \mathrm{m}^{2}$. Only 2 patients presented with gastrointestinal bleeding. The distribution of preoperative risk factors among males and females is listed in online supplementary Table 2.

In detail, $97 \%$ of patients had affection of the SMA. The anatomical distribution of pathologies of mesenteric 


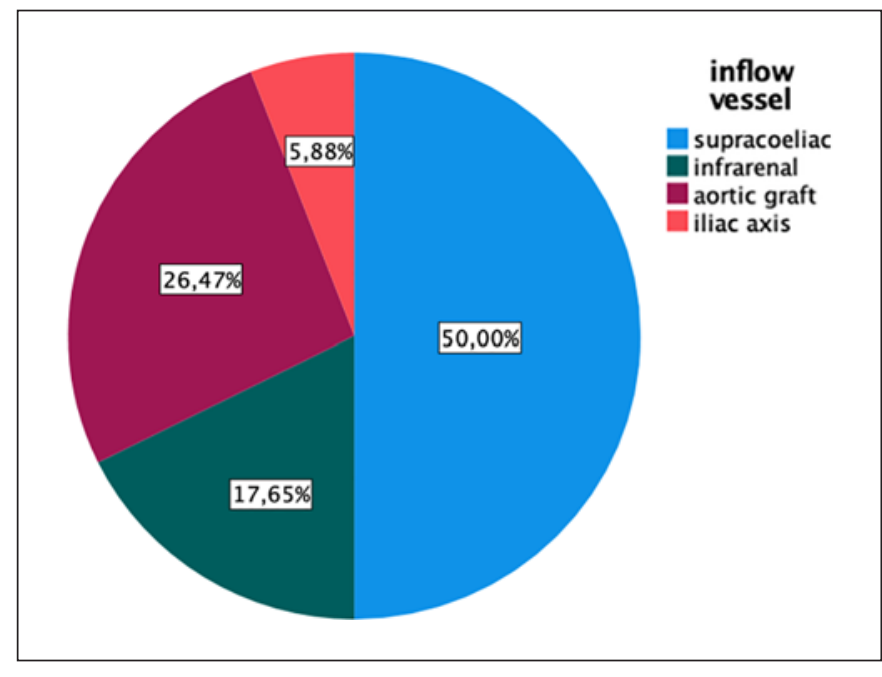

Fig. 3. Frequency of various inflow feeding arteries used for reconstruction.

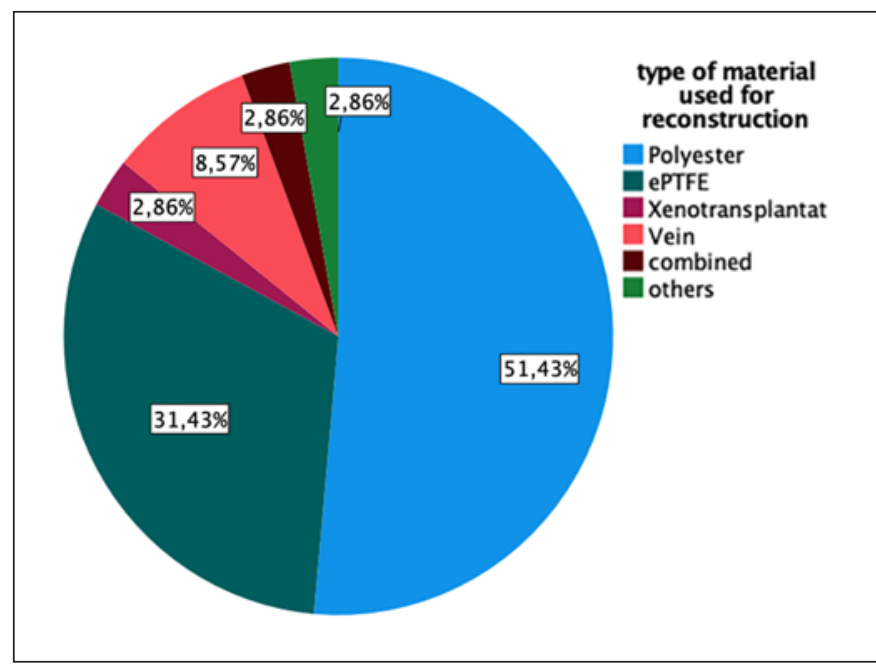

Fig. 4. Distribution according to the type of material used for mesenteric reconstruction (polyester/dacron, ePTFE, vein graft, biologic/xenogenic material, combined reconstruction, and others/ endarterectomy).

arteries is listed in Table 1. The material used for reconstruction included polyester, PTFE, venous, and biological grafts as well as combination of several materials.

Various inflow feeding vessels used in the reconstruction are demonstrated in Figure 3. Different materials for the reconstruction are used as shown in Figure 4.

Eighteen patients $(51.4 \%)$ underwent 1-vessel reconstruction, whereas 17 patients (48.6\%) underwent 2 -vessel reconstruction. There was no combined approach of an image-guided intervention and open vascular surgery. The mean $( \pm \mathrm{SD})$ time for cross-clamping of the aorta was $13.8 \pm 9.0 \mathrm{~min}$ and $9.9 \pm 10.2 \mathrm{~min}$ for cross-clamping of the supraceliac aorta, respectively.
The mean length of operation ( \pm SD) was $196 \pm 66.7$ min ranging from 100 to $350 \mathrm{~min}$. The mean hospital stay was 36.6 days, while the mean stay on the intensive care unit was 17.3 days.

During the postoperative period, the primary patency rate was $82.9 \%$, whereas the clinical patency was $91.4 \%$, and the secondary patency rate was $85.7 \%$. At 1 year, the primary and clinical patency rate was $95.5 \%$. After 5 years, the primary and clinical patency rate was reported to be $77.1 \%$ of the patients' group $(n=27 / 35)$, whereas 8 patients were lost to follow-up. A superficial surgical site infection occurred in 4 patients (11.4\%) who were successfully treated with conservative wound management, whereas a deep surgical site infection including graft infection was reported in only 2 patients (5.7\%), which has been treated surgically. Cardiovascular events occurred in only $3 / 35$ patients $(8.6 \%)$; respiratory complications including pneumonia, pleural effusion, and respiratory decompensation occurred in $42.9 \%$ of patients $(n=15 / 35)$. There was an increase of the serum creatinine level in 5/35 patients (14.3\%); self-limited hepatobiliary complications including self-limiting pancreatitis and acalculous cholecystitis developed in $4 / 35$ patients (11.4\%).

Additional complications included cerebrovascular events, which occurred in 8 patients (22.9\%). Postoperative surgical site bleeding occurred in $40 \%$ of patients ( $n=14 / 35)$; of those, 9 patients required reoperation to stop the bleeding or to remove the intra-abdominal hematoma. Peripheral vascular ischemia in the lower extremities developed in only 2 patients (5.7\%). Portal vein thrombosis occurred in 1 patient $(2.9 \%)$. Pulmonary embolism developed in 1 patient $(2.9 \%)$. Twenty percent of patients $(n=7 / 35)$ developed urinary tract infection, which was successfully treated with conservative management using antibiotics. Upper gastrointestinal bleeding occurred in $8.6 \%(n=3 / 35)$.

Taken together, the specific complication rate was $62.9 \%$, whereas the general complication rate was $57.1 \%$, resulting in an overall morbidity of $77.1 \%$. The overall mortality was $20 \%$.

There was no significant difference in the postoperative morbidity in the early postoperative period, comparing retrograde with antegrade group $(p=0.285)$. The 2 -vessel group had a trend of higher morbidity $(p=0.06)$ versus 1-vessel group.

At 1 year postoperatively, both patients who had undergone retrograde versus antegrade and 2-vessel versus 1 -vessel reconstruction showed no significant difference regarding morbidity ( $p=0.715$ and $p=0.466$, respectively). At 5 -years follow-up, in patients with retrograde versus antegrade reconstruction, there was no different morbidity $(p=0.62)$; however, the 2 -vessel group had a significantly higher morbidity $(p=0.009)$ than that of the 1 -vessel group. Consistently, postoperative mortality was 
Table 2. Morbidity and mortality (early postoperatively, at 1 year and 5 years) with their correlation to preoperative risk factors

\begin{tabular}{|c|c|c|c|}
\hline \multirow[t]{2}{*}{ Analyzed risk factor } & \multicolumn{3}{|l|}{ Morbidity/mortality } \\
\hline & $\begin{array}{l}\text { early postoperative } \\
p \text { value }\end{array}$ & $\begin{array}{l}\text { at } 1 \text { year } \\
p \text { value }\end{array}$ & $\begin{array}{l}\text { at } 5 \text { years } \\
p \text { value }\end{array}$ \\
\hline Gender & $0.358 / 0.132$ & $0.594 / 0.164$ & $0.280 / 0.714$ \\
\hline Age & $0.411 / 0.791$ & $0.591 / 0.724$ & $0.388 / 0.359$ \\
\hline Diabetes mellitus & $0.652 / 0.196$ & 0.930/0.139 & $0.829 / 0.438$ \\
\hline Arterial hypertension & $0.652 / 0.207$ & $0.233 / 0.166$ & $0.280 / \mathbf{0 . 0 7 0}$ \\
\hline BMI & $0.536 / 0.289$ & $0.456 / 0.361$ & $0.324 / 0.449$ \\
\hline HLP & $0.632 / 0.100$ & $\mathbf{0 . 0 1 8} * / 0.054$ & $\mathbf{0 . 0 4 0} * / 0.245$ \\
\hline Preoperative TPN & $0.215 / 0.915$ & $0.809 / 0.918$ & $0.308 / 0.185$ \\
\hline History of smoking & $0.173 / 0.475$ & $0.583 / 0.504$ & $0.197 / 0.333$ \\
\hline PAD & $0.020 * / 0.314$ & $0.200 / 0.220$ & $\mathbf{0 . 0 2 4} * / 0.398$ \\
\hline Cerebrovascular disease & $0.970 / 0.314$ & $0.157 / 0.454$ & $0.255 / 0.310$ \\
\hline Renovascular disease & $0.220 / 0.565$ & $0.962 / 0.504$ & $0.732 / 0.155$ \\
\hline CHD & $0.359 / 0.074$ & $0.025 * / 0.017 *$ & $0.130 / 0.038 *$ \\
\hline $\mathrm{CHF}$ & $0.103 / 0.648$ & $0.254 / 0.436$ & $0.412 / 0.268$ \\
\hline CRF & $0.096 / 0.416$ & $0.886 / 0.353$ & $0.088 / 0.464$ \\
\hline Previous malignancy & $0.191 / 0.925$ & $\mathbf{0 . 0 2 5} * / 0.812$ & $0.07 / 0.919$ \\
\hline Previous abdominal surgery & $0.874 / 0.523$ & $0.901 / 0.558$ & $0.952 / 0.310$ \\
\hline Previous bowel surgery & $0.163 / 0.585$ & $0.870 / 0.453$ & $0.914 / 0.398$ \\
\hline Previous peripheral vascular surgery & $0.489 / 0.380$ & $0.318 / 0.139$ & $0.070 / 0.038^{*}$ \\
\hline Previous carotid surgery & $0.946 / 0.295$ & $0.294 / 0.026 *$ & $0.412 / 0.268$ \\
\hline Previous aortic surgery & $0.087 / 0.482$ & $0.739 / 0.362$ & $0.308 / 0.185$ \\
\hline Previous cardiac surgery & $0.765 / \mathbf{0 . 0 2 4} *$ & $0.060 / 0.017^{*}$ & $0.231 / 0.104$ \\
\hline Previous mesenteric surgery & $0.065 / 0.377$ & $0.583 / 0.436$ & $0.732 / 0.919$ \\
\hline
\end{tabular}

BMI, body mass index; HLP, hyperlipoproteinemia; TPN, total parenteral nutrition; PAD, peripheral arterial disease; CHD, coronary heart disease; CHF, congestive heart failure; CRF, chronic renal failure. * Statistically significant.

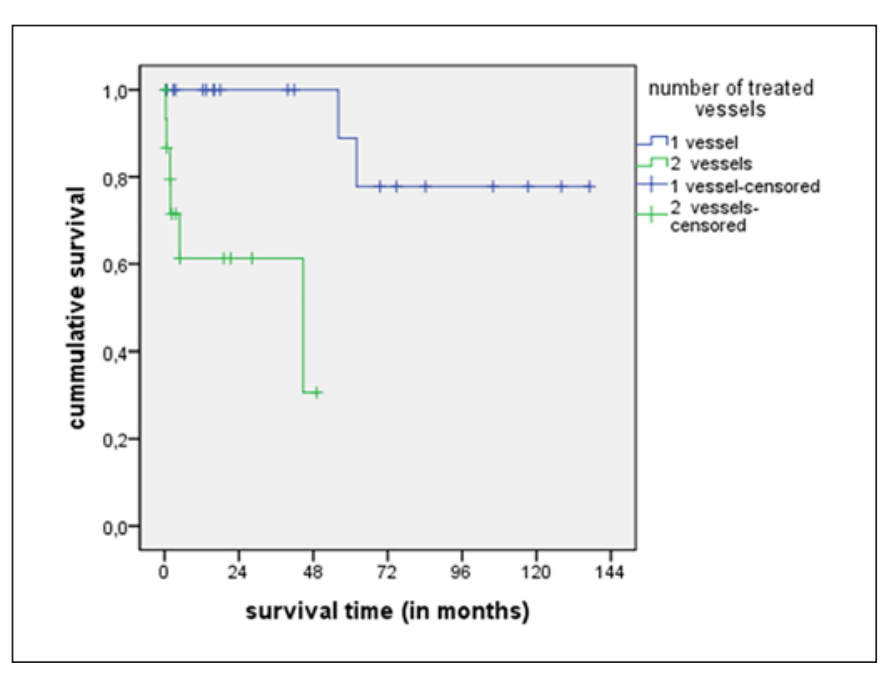

Fig. 5. Cumulative survival comparing 1 -vessel and 2 -vessel groups.

significantly greater in the 2 -vessel group in the early postoperative period $(p=0.016)$, at 1 year $(p=0.005)$, and at 5 years postoperatively $(p=0.003)$, respectively.

The preoperative comorbidities and anatomical factors were analyzed with univariate analysis using the $\chi^{2}$ test to calculate the correlation with morbidity and mortality in the early postoperative period, after 1 year and after 5 years as shown in Table 2. The postoperative outcome including primary patency and postoperative complications in relation to directionality of reconstruction and number of treated vessels and its statistical value is listed in Table 3.

Regarding the survival in relation to the number of reconstructed vessels, there is a statistically significant longer cumulative survival in the 1-vessel group $(p=0.001)$ than that in the 2-vessel group as shown in Figure 5. There was no significant difference regarding the survival of patients who had undergone antegrade versus retrograde reconstruction.

\section{Discussion}

Because of the rarity of the disease and the nature of this single-center study, the authors confronted here the data from the current study with previous reports; there are some similarities as well as differences as listed in Table 4 . The revascularization of the CA by a retrograde bypass, which terminates at the hepatic artery, was described by several authors in many instances [18]. 
Table 3. Postoperative outcome and complications and their correlation to both the directionality of reconstruction (antegrade vs. retrograde) and the number of reconstructed vessels (1-vessel vs. 2-vessel)

\begin{tabular}{|c|c|c|c|c|}
\hline & $\begin{array}{l}\text { Antegrade } \\
(n=21)\end{array}$ & $\begin{array}{l}\text { Retrograde } \\
(n=17)\end{array}$ & $\begin{array}{l}1 \text {-vessel } \\
(n=20)\end{array}$ & $\begin{array}{l}2 \text {-vessel } \\
(n=18)\end{array}$ \\
\hline $\begin{array}{l}\text { Primary patency - early postoperative, } \%, n \\
\quad p \text { value }\end{array}$ & $\begin{array}{l}90.5,19 \\
0.207\end{array}$ & $90.5,19$ & $\begin{array}{l}85,17 \\
0.687\end{array}$ & $77.8,14$ \\
\hline $\begin{array}{l}\text { Primary patency - at } 1 \text { year, } \%, n \\
\quad p \text { value }\end{array}$ & $\begin{array}{l}92.3,12 \\
1.0\end{array}$ & 100,9 & $\begin{array}{l}92.9,13 \\
1.0\end{array}$ & 100,8 \\
\hline $\begin{array}{l}\text { Primary patency - at } 5 \text { years, } \%, n \\
\quad p \text { value }\end{array}$ & $\begin{array}{l}100,4 \\
?\end{array}$ & 100,4 & $\begin{array}{l}100,8 \\
?\end{array}$ & \\
\hline $\begin{array}{l}\text { Cardiac complications, } \%, n \\
\quad p \text { value }\end{array}$ & $\begin{array}{l}14.3,3 \\
0.238\end{array}$ & 0 & $\begin{array}{l}5,1 \\
0.595\end{array}$ & $11.1,2$ \\
\hline $\begin{array}{l}\text { Respiratory complications, } \%, n \\
\quad p \text { value }\end{array}$ & $\begin{array}{l}38.1,8 \\
0.743\end{array}$ & $47.1,8$ & $\begin{array}{l}30,6 \\
0.188\end{array}$ & $55.6,10$ \\
\hline $\begin{array}{l}\text { Renal complications, } \% \\
\quad p \text { value }\end{array}$ & $\begin{array}{l}9.5,2 \\
0.378\end{array}$ & $23.5,4$ & $\begin{array}{l}10,2 \\
0.395\end{array}$ & $22.2,4$ \\
\hline $\begin{array}{l}\text { Hepatobiliary complications, } \%, n \\
\quad p \text { value }\end{array}$ & $\begin{array}{l}9.5,2 \\
0.743\end{array}$ & $47.1,8$ & $\begin{array}{l}5,1 \\
0.188\end{array}$ & $22.2,4$ \\
\hline $\begin{array}{l}\text { Cerebrovascular complications, } \%, n \\
\quad p \text { value }\end{array}$ & $\begin{array}{l}28.6,6 \\
0.257\end{array}$ & $11.8,2$ & $\begin{array}{l}15,2 \\
0.438\end{array}$ & $27.8,5$ \\
\hline $\begin{array}{l}\text { Bleeding, } \%, n \\
\quad p \text { value }\end{array}$ & $\begin{array}{l}38.1,8 \\
1.0\end{array}$ & $41.2,7$ & $\begin{array}{l}25,5 \\
0.096\end{array}$ & $55.6,10$ \\
\hline $\begin{array}{l}\text { Bleeding required reoperation, } \%, n \\
\quad p \text { value }\end{array}$ & $\begin{array}{l}38.1,8 \\
1.0\end{array}$ & $41.2,7$ & $\begin{array}{l}25,5 \\
0.096\end{array}$ & $55.6,10$ \\
\hline $\begin{array}{l}\text { Peripheral ischemia, } \%, n \\
\quad p \text { value }\end{array}$ & $\begin{array}{l}9.5,2 \\
0.492\end{array}$ & 0 & $\begin{array}{l}0 \\
0.218\end{array}$ & $11.1,2$ \\
\hline $\begin{array}{l}\text { Postoperative urinary tract infection, } \%, n \\
\quad p \text { value }\end{array}$ & $\begin{array}{l}14.3,3 \\
0.426\end{array}$ & $29.4,5$ & $\begin{array}{l}20,4 \\
1.0\end{array}$ & $22.2,4$ \\
\hline $\begin{array}{l}\text { Gastrointestinal bleeding, } \%, n \\
\quad p \text { value }\end{array}$ & $\begin{array}{l}4.8,1 \\
0.307\end{array}$ & $17.6,3$ & $\begin{array}{l}10,2 \\
1.0\end{array}$ & $11.1,2$ \\
\hline $\begin{array}{l}\text { Wound infection, } \%, n \\
\quad p \text { value }\end{array}$ & $\begin{array}{l}19,4 \\
0.672\end{array}$ & $11.8,2$ & $\begin{array}{l}10,2 \\
0.383\end{array}$ & $22.2,4$ \\
\hline
\end{tabular}

Table 4. Patients' characteristics noted in previous reports and in the current study $[17,20,21,23-25,28,32-34$, 37-42], in alphabetic order

\begin{tabular}{|c|c|c|c|c|c|}
\hline Author & $\begin{array}{l}\text { Sex ratio } \\
(\mathrm{m} / \mathrm{f})\end{array}$ & $\begin{array}{l}\text { Mean age, } \\
\text { years }\end{array}$ & $\begin{array}{l}\text { Weight loss, } \\
n(\%)\end{array}$ & $\begin{array}{l}\text { Smoking, } \\
n(\%)\end{array}$ & $\begin{array}{l}\text { PAD, } \\
n(\%)\end{array}$ \\
\hline Beebe et al. [32] & $7 / 10$ & 54 & $10 / 10(100)$ & Not reported & Not reported \\
\hline Calderon et al. [25] & $17 / 20$ & 59 & $13 / 20(65)$ & $6 / 20(30)$ & $3 / 20(15)$ \\
\hline Current study $n(\%)$ & $20 / 38(53)$ & 64 & $32 / 38(84)$ & 39/38 (78.9) & $23 / 38(60.5)$ \\
\hline Davenport et al. [37] & $119 / 156$ & 65 & $54 / 156(35)$ & $77 / 156(49)$ & $37 / 156(24)$ \\
\hline Foley et al. [38] & $31 / 49$ & 62 & Not reported & $48 / 49(98)$ & $28 / 49(57)$ \\
\hline Gentile et al. [20] & $16 / 26$ & 59 & Not reported & $25 / 26(96)$ & $16 / 26(62)$ \\
\hline Geroulakos et al. [39] & $9 / 10$ & 66 & $10 / 10(100)$ & Not reported & Not reported \\
\hline Hollier et al. [34] & $11 / 56$ & 50 & $55 / 56(98)$ & Not reported & Not reported \\
\hline Jimenez et al. [24] & $33 / 47$ & 62 & $39 / 47(83)$ & $43 / 47(91)$ & $23 / 47(49)$ \\
\hline Johnston et al. [33] & $11 / 21$ & 58 & $1 / 21(5)$ & $19 / 21(90)$ & $17 / 21(81)$ \\
\hline Kihara et al. [40] & $30 / 42$ & 60 & Not reported & $37 / 42(88)$ & Not reported \\
\hline Kruger et al. [41] & $22 / 39$ & 65 & $37 / 39(95)$ & $36 / 39(92)$ & $16 / 39(41)$ \\
\hline Mateo et al. [23] & $60 / 85$ & 62 & $74 / 85(87)$ & $75 / 85(88)$ & Not reported \\
\hline McMillan et al. [17] & $17 / 25$ & 61 & $21 / 25(84)$ & $22 / 25(88)$ & $9 / 25(36)$ \\
\hline Moawad et al. [28] & $19 / 24$ & 58 & $14 / 24(58)$ & $20 / 24(83)$ & Not reported \\
\hline Rheudasil et al. [21] & $21 / 41$ & 59 & $23 / 41(56)$ & $36 / 41(88)$ & $18 / 41(44)$ \\
\hline Zelenock et al. [42] & $13 / 23$ & 56 & $23 / 23(100)$ & Not reported & Not reported \\
\hline
\end{tabular}


Table 5. Postoperative outcome of the current study and of previous reports at the follow-up period $[23,38,40,41$, 43-46]

\begin{tabular}{lllllll}
\hline Author & $\begin{array}{l}\text { Patients, } \\
n / \text { vessels, } n\end{array}$ & $\begin{array}{l}\text { Technical } \\
\text { success (\%) }\end{array}$ & $\begin{array}{l}\text { Mortality } \\
(\%)\end{array}$ & $\begin{array}{l}\text { Morbidity } \\
(\%)\end{array}$ & $\begin{array}{l}\text { Recurrence } \\
(\%)\end{array}$ & $\begin{array}{l}1^{\circ} \text { patency } \\
(\%)\end{array}$ \\
\hline Cho et al. [43] & $25 / 41$ & 100 & 0 & 21 & Not reported & 57 \\
Current study & $38 / 55$ & 100 & 13.2 & 48.4 & 4.5 & 81.6 \\
Foley et al. [38] & $28 / 28$ & 100 & 3 & Not reported & 10 & 79 \\
Illuminati et al. [44] & $11 / 12$ & 100 & 0 & 27 & 10 & 90 \\
Kihara et al. [40] & $42 / 52$ & 100 & 10 & 35 & 10 & 65 \\
Kruger et al. [41] & $39 / 67$ & 100 & 2.5 & 12 & 5 & 92 \\
Leke et al. [45] & $17 / 25$ & 100 & 6 & 41 & 0 & 100 \\
Mateo et al. [23] & $85 /$ not reported & 100 & 8 & 23 & 20 & 71 \\
Park et al. [46] & $98 / 179$ & 100 & 5 & 21 & 8 & Not reported \\
\hline
\end{tabular}

Courbier et al. [19] attributed substantial importance to the hepatic artery. He performed an end-to-end anastomosis on it or reimplanted it, after transection, to the side of an aortomesenteric graft.

In the current study, the common hepatic artery was revascularized in 1 case via the left common iliac artery using venous conduit bypass. This avoided the necessity of prolonged cross-clamping of the supraceliac aorta. However, in this report, a clamping time of only $9.8 \pm 10.2$ min was observed.

In this report, no case with pathological involvement of the SMA alone was included, although other authors have described patients with CMI in the presence of pathological changes at only 1 single mesenteric vessel, usually the SMA $[20,21]$ or rarely the CA [8]. It is generally agreed that evidence of severe occlusive disease that involves at least 2 of the 3 mesenteric vessels is necessary to support the diagnosis of CMI [22].

The current analysis demonstrated that $30 \%$ of patients experienced at least 1 major complication during their hospitalization. Table 5 summarizes the clinical outcome of the current study in comparison to other studies in the literature. A low recurrence rate of CMI and high 1-year patency rate of 4.5 and $95.5 \%$, respectively, are confronted by a mortality and morbidity of the upper range, which has been reported here very honestly.

In the current study, the mesenteric vessels were reconstructed using antegrade bypass in 19 patients (54.3\%) and retrograde graft implantation in 16 patients (45.7\%). In a study from the Cleveland Clinic, $40 \%$ of patients underwent retrograde bypass, whereas only $29 \%$ underwent antegrade bypass; the remaining patients underwent other reconstructions including local endarterectomy with local patch angioplasty. They performed 1-vessel reconstruction in $75 \%$ of patients; the residual $25 \%$ underwent 2-vessel reconstruction [23].

A few studies reported patients with CMI who had been treated with anterograde supraceliac aortomesen- teric bypass grafting through upper abdominal exposure and pancreatic displacement to expose the SMA [24]. These authors saw advantages in this technique because there was:

1. less turbulence in blood flow,

2. less bypass compression by the mesentery,

3. prolonged patency of the vessel reconstructions with better flow capabilities, and

4. easier technical handling than retrograde bypass grafting.

In addition, the arteriosclerosis is usually less manifested at the supraceliac segment of the aorta. In contrast, many authors favor the better accessible approach to the infrarenal aorta [23].

Furthermore, elderly patients and those with cachexia or severe cardiac, pulmonary, and renal dysfunction are frequently not good candidates for aortic procedures. One of the main problems in retrograde bypass grafting is bypass kinking because of the mobility of the SMA.

Retrograde prosthetic bypass grafting to the SMA was performed alone or in conjunction with aortic reconstruction in $42.4 \%$ of patients in this current study. Thus, the advantage of not necessitating dissection or crossclamping of the supraceliac aorta was found in the current study, which is a preference advocated by other authors $[18,25-27]$. The major disadvantage of this approach is that care must be taken to place the graft in a near-vertical orientation from its origin to its termination to minimize the tendency to kink when the viscera return to its normal anatomical location [28,29].

Although there are strong proponents for antegrade bypass reconstruction, there is no statistical superiority yet, as has been shown in a randomized controlled trial because of the rarity of the disease. The antegrade orientation allows for a short segment bypass, which:

1. has no propensity to kink,

2. provides direct inline flow with low turbulence, and

3 . avoids direct contact with the bowel $[8,28-33]$. 
However, it was found in the current study that the comparison of the antegrade versus retrograde group shows a slight trend of a higher primary patency rate in the early postoperative time frame $(89.5 \%$ vs. $75.0 \%, p=$ 0.379). This difference was not found at longer follow-up time points, such as at 1 year $(92.3 \%$ vs. $100 \%$, respectively, $p=1.0)$ and 5 years (100\% primary patency in both groups) for the remaining patients. There were no significant differences of the complication and survival rates comparing the antegrade and retrograde groups except in the major postoperative bleeding. The retrograde group had only a trend of more major postoperative bleeding probability than in the antegrade group $(37.5 \%$ vs. $15.8 \%$, $p=0.245$ ).

Hollier et al. [34] found that there was a $29 \%$ recurrence rate of symptoms after revascularization of 2 of 3 involved vessels. In contrast to a single-vessel reconstruction, the recurrence rate was about $50 \%$. Thus, they suggested that although single-vessel revascularization may relieve symptoms, the optimal long-term result can be obtained by complete revascularization of all stenotic vessels. A complete revascularization was also recommended by McAfee et al. [35].

In the current study, the benefits of complete revascularization (rather related to the 2-vessel group), however, were attempted to be obtained, confronted by a trend of more early postoperative complications ( $88.2 \%$ vs. $55.6 \%$, $p=0.06)$. The mortality in the early postoperative period was higher in the 2 -vessel group ( $31.3 \%$ vs. $0, p=0.016)$, which was statistically significant.

Although the postoperative morbidity at 1 year was higher in the 2 -vessel versus 1 -vessel group (57.1\% vs. $40 \%$, respectively), it did not show any significant difference. Nevertheless, the morbidity of the 2-vessel versus 1 -vessel group at 5 years ( $100 \%$ vs. $33 \%)$ was significantly different $(p=0.0094)$. The mortality was greater in the 2 -vessel versus 1 -vessel group with a statistically significance in the early postoperative period $(31.38 \%$ vs. $0, p=$ $0.016)$ and at 1 year ( $50 \%$ vs. $0, p=0.005)$ and at 5 years $(100 \%$ vs. $11 \%, p=0.003)$.

Tertiary referral centers have reported excellent results with open reconstructions, including a recent series from the Mayo Clinic, with a mortality of $0.9 \%$ in low-risk patients [36]. In contrast, in the study presented here, rather consecutive patients matching the inclusion and exclusion criteria (as appropriate indicated), with (partially) a remarkable number and spectrum of risk factors (as listed in online suppl. Table 1,2) were enrolled, finally resulting in a higher mortality as honestly reported. Regarding overall survival, the 1-vessel group showed superiority above the 2-vessel group, with a significant difference $(p=0.001)$.

Implications of the study confirm that mastering a variety of surgical techniques can provide durable relief of mesenteric ischemia (symptoms) and long-term symptom-free survival. The vascular surgeon should be prepared to use all the available techniques and to tailor the operative strategy to the specific needs of the individual patient.

This study has the usual limitations of any retrospective study, which are assumed to have more bias since the study operations, data collected, data entry, and data quality assurance were not planned ahead of time. It also encompasses a relatively small number of patients. These shortcomings, however, highlight a common problem regarding the CMI: its rareness.

It is not likely that a single center can gather a large enough case series during a relatively short time period in order to provide substantial data from a prospective randomized study. Finally, this study represents a retrospective report, and surgeons' bias and patients' conditions that affected the choice of conduit could not be satisfyingly identified.

\section{Conclusion}

The current report represents outcomes in contemporary practice for operative treatment of CMI. Mesenteric reconstruction in case of CMI can be performed safely and effectively with an acceptable mortality. Although mortality was higher in patients with vein grafts than those with prosthetic conduit, it is believed that the patient condition at the time of operation was the primary determinate of the outcome. Bowel resection was required in some patients, indicating that patients with CMI can progress to bowel infarction. Therefore, it is critically important to revascularize patients expeditiously before the development of bowel infarction, a condition that increases the risk of operative mortality.

The use of 2-vessel reconstruction did not improve the patency of bypass and has resulted in higher complication rates. The survival rate has been reported being superior in the 1-vessel reconstruction group. Conceding the uncertainties for the number of vessels to be reconstructed and directionality of reconstruction, the vascular surgeon should currently attempt to reconstruct using the antegrade reconstruction of the most affected mesenteric artery if the anatomy is feasible. In summary, the resulting main points of the presented study are:

1. There is a great importance of early reconstruction of symptomatic CMI to avoid bowel infarction, and

2. Reconstruction of 1 vessel in $\mathrm{CMI}$ is more favorable. 


\section{Acknowledgment}

The authors are grateful for the assistance and support by the employees of the Division of Vascular Surgery, Dept. of General, Abdominal, Vascular and Transplant Surgery, Otto-von-Guericke University of Magdeburg with University Hospital, to document the amount of data in the registry, data monitoring, data validation, and proof of plausibility. In addition, the authors give thanks to Ronny Otto, B.Sc., for statistical advice.

\section{Statement of Ethics}

Data generation, documentation, and evaluation were performed according to prerequisites of data protection law of the German district Saxony-Anhalt and according to the federal law. The study was performed according to the requirements of the "Declaration of Helsinki for Biomedical Research from 1964" by the "World's Medical Association" and its further amendments as well as the policy of the institutional Ethics Committee. With regard to the study concept, it can be stated that a (potential) danger for study participants can be definitely excluded. The statement of an Ethics Committee is not required since, in particular, only patient-associated data were registered independently of the (specific interests of single) patients. There is no imponderable risk or side effect for the patient as it may become possible in the use of any medication. Furthermore, the register with patient-associated data has been led according to the requirements of the German "Landes-und Bundesdatenschutzgesetz"; and then, data were evaluated anonymously without any possible interference to an individual patient. In addition, data have been monitored, validated, and evaluated at an institution close to a university hospital, a tertiary center, and with an associated University Medical School; one of their basic tasks is (according to the "Hochschulmedizingesetz" in Germany) to perform clinical research in addition to clinical care for patients. Last but not the least, leading such register of patient data can be considered close to epidemiological studies, which do not need any statement of an Ethics Committee as well as according to the "Allgemeinen Vertragsbedingungen" of the local contract between the physician and the patient ("Arzt-Patienten-Vertrag") in its current version from 2006, article [\$] 16, paragraph [subparagraph] 4 , it is not permitted to evaluate anonymous data. With regard to the availability of data and materials, each patient signed informed consent form prior to (i) surgery includ- ing appropriate explanation of the surgical intervention and potential complications and (ii) generation and documentation of data in the patient data registry.

\section{Conflict of Interest Statement}

M.E., F.M., R.D., and Z.H. declare that no potential conflicts of interest exist. This includes, but is not limited to, any financial relationship with regard to the research presented. There is no financial interest/arrangement with 1 or more organizations that could be perceived as a real or apparent conflict of interest in the context of the subject of this article for each of the authors.

\section{Funding Sources}

This study did not receive any specific grant from funding agencies in the public, commercial, or nonprofit organization sectors.

\section{Author Contributions}

M.E. contributed to conceptualization, data curation, formal analysis, investigation, and methodology, project administration, resources, supervision, validation, visualization, and roles/writing - original draft. F.M. contributed to data curation, formal analysis, resources, software, visualization, and writing - review and editing. R.D. contributed to data curation, formal analysis, project administration, resources, and writing - review and editing. Z.H. contributed to conceptualization, formal analysis, investigation, methodology, project administration, validation, and writing - review and editing. All the authors have read and approved the manuscript.

\section{Data Availability Statement}

The data that support the findings of this study are not publicly available due to their containing information that could compromise the privacy of research participants but are available from corresponding author (F.M.) and first author (M.E.) upon reasonable request.

\section{References}

1 Feldman M, Friedman LS, Brandt LJ. Sleisenger and Fordtran's gastrointestinal and liver disease E-book: pathophysiology, diagnosis, management. In: Feldman M, Friedman LS, Brandt LJ, editors. Expert consult premium edition-enhanced online features. Elsevier Health Sciences; 2010. Vol. 1.

2 Allbutt C, Rolleston R. System of medicine. London, UK: Macmillan; 1909.

3 Chiene J. Complete obliteration of the coeliae and mesenteric arteries: the viscera receiving their blood-supply through the extra-peritoneal system of vessels. J Anat Physiol. 1868; 3(Pt 1):65.

4 Councilman W. Three cases of occlusion of the superior mesenteric artery. Boston Med Surg J. 1894;130(17):410-1.
5 Goodman EH. Angina abdominis.1. Am J Med Sci. 1918;155(4):524-8.

6 Shaw R, Maynard E 3rd. Acute and chronic thrombosis of the mesenteric arteries associated with malabsorption: a report of two cases successfully treated by thromboendarterectomy. New Engl J Med. 1958;258(18):874-8.

7 Morris GC, Jr, Crawford ES, Cooley DA, Debakey ME. Revascularization of the celiac and superior mesenteric arteries. Arch Surg. 1962; 84(1):95-107.

8 Stoney RJ, Ehrenfeld WK, Wylie EJ. Revascularization methods in chronic visceral ischemia caused by atherosclerosis. Ann Surg. 1977;186(4):468-76.

9 Leschi JP, Coggia M, Goëau-Brissonnière O. Retrograde aortomesenteric bypass with tun- neling behind the left renal pedicle. Ann Vasc Surg. 2001;15(4):503-6.

10 Van Bockel JH, Geelkerken RH, Wasser MN. Chronic splanchnic ischaemia. Best Pract Res Clin Gastroenterol. 2001;15(1):99-119.

11 Krupski WC, Selzman CH, Whitehill TA. Unusual causes of mesenteric ischemia. Surg Clin North Am. 1997;77(2):471-502.

12 Moawad J, Gewertz BL. Chronic mesenteric ischemia. Clinical presentation and diagnosis. Surg Clin North Am. 1997;77(2):357-69.

13 Oderich GS, Gloviczki P, Bower TC. Open surgical treatment for chronic mesenteric ischemia in the endovascular era: when it is necessary and what is the preferred technique? Semin Vasc Surg. 2010;23(1): 36-46. 
14 Hildebrand HD, Zierler RE. Mesenteric vascular disease. Am J Surg. 1980;139(2):188-92.

15 Horton KM, Fishman EK. Multidetector CT angiography in the diagnosis of mesenteric ischemia. Radiol Clin North Am. 2007;45(2): 275-88.

16 Lee BY, Assadi C, Madden JL, Kavner D, Trainor FS, McCann WJ. Hemodynamics of arterial stenosis. World J Surg. 1978;2(5) 621-40.

17 McMillan WD, McCarthy WJ, Bresticker MR, Pearce WH, Schneider JR, Golan JF, et al. Mesenteric artery bypass: objective patency determination. J Vasc Surg. 1995;21(5):72940.

18 Baur GM, Millay DJ, Taylor LM Jr, Porter JM. Treatment of chronic visceral ischemia. Am J Surg. 1984;148(1):138-44.

19 Courbier R, Ferdani M, Jausseran J, Bergeron P, Aboukhater R, Chbib A. Pontages artériels digestifs: résultats cliniques lointains. J Chir. 1990;127(3):129-35.

20 Gentile AT, Moneta GL, Taylor LM Jr, Park TC, McConnell DB, Porter JM. Isolated bypass to the superior mesenteric artery for intestinal ischemia. Arch Surg. 1994;129(9): 926-2.

21 Rheudasil JM, Stewart MT, Schellack JV Smith RB, Salam AA, Perdue GD. Surgical treatment of chronic mesenteric arterial insufficiency. J Vasc Surg. 1988;8(4):495-500.

22 Costa AF, Chidambaram V, Lee JJ, Asquith J, Skaff ER, Thipphavong S. Multidetector computed tomography of mesenteric ischaemia. Insights Imaging. 2014;5(6):657-66.

23 Mateo RB, O’Hara PJ, Hertzer NR, Mascha EJ, Beven EG, Krajewski LP. Elective surgical treatment of symptomatic chronic mesenteric occlusive disease: early results and late outcomes. J Vasc Surg. 1999;29(5):821-32.

24 Jimenez JG, Huber TS, Ozaki CK, Flynn TC, Berceli SA, Lee WA, et al. Durability of antegrade synthetic aortomesenteric bypass for chronic mesenteric ischemia. J Vasc Surg. 2002;35(6):1078-84.

25 Calderon M, Reul GJ, Gregoric ID, Jacobs MJ Duncan JM, Ott DA, et al. Long-term results of the surgical management of symptomatic chronic intestinal ischemia. J Cardiovasc Surg. 1992;33(6):723-8.

26 McCollum CH, Graham JM, DeBakey ME. Chronic mesenteric arterial insufficiency: results of revascularization in 33 cases. South Med J. 1976;69(10):1266-8.

27 Taylor LM Jr, Porter JM. Treatment of chronic intestinal ischemia. Sem Vasc Surg. 1990;3: 186-99.

28 Moawad J, McKinsey JF, Wyble CW, Bassiouny HS, Schwartz LB, Gewertz BL. Current results of surgical therapy for chronic mesenteric ischemia. Arch Surg. 1997;132(6):613-9.

29 Rapp JH, Reilly LM, Qvarfordt PG, Goldstone J, Ehrenfeld WK, Stoney RJ. Durability of endarterectomy and antegrade grafts in the treatment of chronic visceral ischemia. J Vasc Surg. 1986;3(5):799-806.

30 Cunningham CG, Reilly LM, Rapp JH, Schneider PA, Stoney RJ. Chronic visceral ischemia. Three decades of progress. Ann Surg. 1991;214(3):276-8.

31 MacFarlane SD, Beebe HG. Progress in chronic mesenteric arterial ischemia. J Cardiovasc Surg. 1989;30(2):178-84.

32 Beebe HG, MacFarlane S, Raker EJ. Supraceliac aortomesenteric bypass for intestinal ischemia. J Vasc Surg. 1987;5(5):749-54.

33 Johnston KW, Lindsay TF, Walker PM, Kalman PG. Mesenteric arterial bypass grafts: early and late results and suggested surgical approach for chronic and acute mesenteric ischemia. Surgery. 1995;118(1):1-7.

34 Hollier LH, Bernatz PE, Pairolero PC, Payne WS, Osmundson PJ. Surgical management of chronic intestinal ischemia: a reappraisal. Surgery. 1981;90(6):940-6.

35 McAfee MK, Cherry KJ Jr, Naessens JM, Pairolero PC, Hallett JW, Gloviczki P, et al. Influence of complete revascularization on chronic mesenteric ischemia. Am J Surg. 1992; 164(3):220-4

36 Oderich GS, Malgor RD, Ricotta JJ. Open and endovascular revascularization for chronic mesenteric ischemia: tabular review of the literature. Ann Vasc Surg. 2009;23(5):700-12.
37 Davenport DL, Shivazad A, Endean ED. Short-term outcomes for open revascularization of chronic mesenteric ischemia. Ann Vasc Surg. 2012;26(4):447-53.

38 Foley MI, Moneta GL, Abou-Zamzam AM Jr, Edwards JM, Taylor LM, Yeager RA, et al. Revascularization of the superior mesenteric artery alone for treatment of intestinal ischemia. J Vasc Surg. 2000;32(1):37-47.

39 Geroulakos G, Tober JC, Anderson L, Smead WL. Antegrade visceral revascularisation via a thoracoabdominal approach for chronic mesenteric ischaemia. Eur J Vasc Endovasc Surg. 1999;17(1):56-9.

40 Kihara TK, Blebea J, Anderson KM, Friedman D, Atnip RG. Risk factors and outcomes following revascularization for chronic mesenteric ischemia. Ann Vasc Surg. 1999;13(1) 37-44.

41 Kruger AJ, Walker PJ, Foster WJ, Jenkins JS, Boyne NS, Jenkins J. Open surgery for atherosclerotic chronic mesenteric ischemia. J Vasc Surg. 2007;46(5):941-5.

42 Zelenock GB, Graham LM, Whitehouse WM Jr, Erlandson EE, Kraft RO, Lindenauer SM, et al. Splanchnic arteriosclerotic disease and intestinal angina. Arch Surg. 1980;115(4): 497-501.

43 Cho JS, Carr JA, Jacobsen G, Shepard AD, Nypaver TJ, Reddy DJ. Long-term outcome after mesenteric artery reconstruction: a $37-$ year experience. J Vasc Surg. 2002;35(3):45360.

44 Illuminati G, Caliò FG, D’Urso A, Papaspiropoulos V, Mancini P, Ceccanei G. The surgical treatment of chronic intestinal ischemia: results of a recent series. Acta Chir Belg. 2004, 104(2):175-83.

45 Leke MA, Hood DB, Rowe VL, Katz SG, Kohl $\mathrm{RD}$, Weaver FA. Technical consideration in the management of chronic mesenteric ischemia. Am Surg. 2002;68(12):1088-92.

46 Park WM, Cherry KJ, Chua HK, Clark RC, Jenkins G, Harmsen WS, et al. Current results of open revascularization for chronic mesenteric ischemia: a standard for comparison. J Vasc Surg. 2002;35(5):853-9. 